\title{
A Novel Approach of Potent Antioxidant and Antimicrobial Agents Containing Coumarin Moiety Accompanied with Cytotoxicity Studies on the Newly Synthesized Derivatives
}

\author{
Huda R. M. Rashdan ${ }^{\mathrm{a} *}$, Sami M. Nasr ${ }^{\mathrm{b}}$, Heba A. El-Refai ${ }^{\mathrm{a}}$, Mohamed S. Abdel-Aziz \\ ${ }^{a}$ Chemistry of natural and microbial products department, Pharmaceutical and drug industry research division, National research center, Giza, Egypt. \\ ${ }^{\mathrm{b}}$ Theodor Bilharz Research Institute, Biochemistry and Molecular Biology and Medicinal chemistry Department, Giza, Egypt. \\ ${ }^{c}$ Microbial Chemistry Department, Genetic Engineering and Biotechnology Division, National research center, Giza, Egypt.
}

\begin{tabular}{|c|c|}
\hline ARTICLE INFO & ABSTRACT \\
\hline Article history: & \multirow{6}{*}{$\begin{array}{l}\text { 3-Amino-6-(2-oxo- } 2 H \text {-chromen-3-yl)pyridine-2-carbonitrile }(\mathbf{2}) \text { was synthesized via the reaction of 3- } \\
\text { (dimethylamino)acryloyl-2H-chromen-2-one (1) with malononitrile. The reactivity of the } \\
\text { 2-amino-3-cyanopyridine derivative } \mathbf{2} \text { toward a variety of electrophiles as triethylorthoformate followed by } \\
\text { nitrogenous nucleophiles as hydrazine hydrate was investigated. Also, enamine } \mathbf{1} \text { was utilized as precursor for } \\
\text { synthesis of new 3-heteroarylsubstituted coumarins, in which it reacted with a series of hydrazonoyl halides and } \\
\text { p-bromobenzenediazonium chloride to yield different3-substituted coumarins. The structures of the newly } \\
\text { synthesized derivatives were confirmed by different spectral tools (IR, } \mathrm{H}^{1} \mathrm{NMR} \text { mass spectrometry and } \\
\text { elemental analysis). All the newly synthesized compounds were screened for their antioxidant, antimicrobial } \\
\text { activities and cytotoxicity. The preliminary structure-activity relationship was discussed to illustrate the } \\
\text { essential structure requirements. }\end{array}$} \\
\hline Received on: 01/03/2017 & \\
\hline Accepted on: 10/05/2017 & \\
\hline Available online: $30 / 07 / 2017$ & \\
\hline Key words: & \\
\hline $\begin{array}{l}\text { Coumarins; enamines; } \\
\text { antioxidant agents; } \\
\text { antimicrobial agents and } \\
\text { cytotoxicity. }\end{array}$ & \\
\hline
\end{tabular}

\section{INTRODUCTION}

Coumarins are an extremely important family of heterocyclic compounds owing to their presence in large biologically active substances and are used as pharmaceutical agents. Coumarins are natural extract products; it is the secondary metabolites in plant species, especially in the plants belong to families rutaceae and umbrelliferae (Dean, 1952). Coumarins are classified into simple coumarins, such as pyrano and furanocoumarins and other coumarins that can be divided into linear and angular types according to the different substituent group in the ring. Natural and synthetic derivatives of coumarins have wide range of biological and pharmacological

\footnotetext{
* Corresponding Author

Email: hudadawoud20@yahoo.com

Tel:+201157711744
}

activities such as, as anti-oxidant, anti-HIV, anti-bacterial (ShwuChen et al., 2016), antifungals (Ping-Ping et al, 2017), anticancer (Salem et al, 2016), and anti-inflammatory (Witaicenis et al, 2014). Alzheimer's disease, atherosclerosis, osteoarthritis and other diseases as well as many types of cancer diseases (Medzhitov, 2010) have been attributed to inflammatory processes in their pathogenesis. Coumarin derivative exerts its anti-inflammatory action in rat lung edema by inhibiting the TNF- $\alpha$ expression and increasing the VCAM-1 and ICAM-1 expression level (Li et al., 2012). Recent studies have also been found that coumarins possess anti-leishmanial activity (Mislaine et al., 2017). Substituted coumarins have potential pharmaceutical activities as antidiabetic activity (Sung et al., 2017) and they also used as additives to food and cosmetics (Kennedy and Thornes, 1997). These investigations have revealed their potentials as antioxidant, antimicrobial and cytotoxicity. This investigation has been undertaken with the aim of synthesizing novel Coumarin derivatives and evaluating their biological activities. 


\section{EXPERIMENTAL}

All melting points were determined on an electrothermal apparatus and are uncorrected. IR spectra were recorded $(\mathrm{KBr}$ discs) on Shimadzu FT-IR 8201 PC spectrophotometer. $\mathrm{H}^{1} \mathrm{NMR}$ spectra were recorded in $\left(\mathrm{CD}_{3}\right)_{2} \mathrm{SO}$ solutions on JNM-LA 400 FTNMR system spectrometer and chemical shifts are expressed in $\delta$ ppm units using TMS as an internal reference. Mass spectra were recorded on a GC-MS QP1000 EX Shimadzu. Elemental analyses were carried out at the microanalytical center of Cairo University. Hydrazonoyl halides (Shawlli and Abdelhamid, 1976) were prepared as previously mentioned.

\section{Chemistry}

2-amino-6-(2-oxo-2H-chromen-3-yl)pyridine-3-carbonitrile (2).

A mixture of 3-(3-(dimethylamino)acryloyl)- $2 \mathrm{H}$ chromen-2-one (1)(1.2 gm, 5mmol) and malononitrile $(0.33 \mathrm{gm}$, $5 \mathrm{mmol})$ was heated in acetic acid(10 $\mathrm{ml})$ under reflux in the presence of catalytic amount of ammonium acetate $(0.38 \mathrm{gm}$, $5 \mathrm{mmol}$ ) for $3 \mathrm{hrs}$. on cooling, the separated solid was filtered, washed with water and crystallized from acetic acid to afford 2 as orange crystals in a good yield. Yield:82\%; mp.:208-210 ${ }^{\circ} \mathrm{C}$; FT$\mathrm{IR}\left(\mathrm{KBr}, \mathrm{cm}^{-1}\right): 3409,3330 v\left(\mathrm{NH}_{2}\right), 2208 v(\mathrm{CN}), 1677 v(\mathrm{C}=\mathrm{O}), 1606$ $v(\mathrm{C}=\mathrm{N}) ; \mathrm{H}^{1} \mathrm{NMR}\left(400 \mathrm{MHz}, \mathrm{DMSO}-d_{6}\right): \delta=7.3-7.8(\mathrm{~m}, 6 \mathrm{H}, \mathrm{Ar}-\mathrm{H})$, 8.51(s, $1 \mathrm{H}, \mathrm{C} 4-\mathrm{H}$ of coumarin), 6.5(s, 2H, $\left.\mathrm{NH}_{2}\right) ; \mathrm{MS}$ : $\mathrm{M} / \mathrm{z}[\%]=264(\mathrm{M}+1,4 \%), 263\left(\mathrm{M}^{+}, 17 \%\right), 216(8.08 \%), 174(20 \%)$, 145(43.99\%), 110(1.63\%), 99(100\%), 77(75.23\%); Anal. calcd. for $\mathrm{C}_{15} \mathrm{H}_{9} \mathrm{~N}_{3} \mathrm{O}_{2}$ (263): C,68.44; H,3.45; N,15.96\%. Found: C,68.45; $\mathrm{H}, 3.42 ; \mathrm{N}, 16.93 \%$.

\section{Ethyl N-(3-cyano-6-(2-oxo-2H-chromen-3-yl)pyridine-2-yl) carboximidate (3)}

A mixture of (2) (2.3gm, 5mmol) and triethylorthoformate $(1.48 \mathrm{gm}, 10 \mathrm{mmol})$ in acetic anhydride $(20 \mathrm{ml})$ was heated under reflux for 6hrs. the reaction mixture was poured onto ice $(30 \mathrm{gm})$. The resulting solid was collected and recrystallized from ethanol to give $\mathbf{3}$ as brown crystals. Yield:72\% ; mp.: 172-174 ${ }^{\circ} \mathrm{C}$; FT-IR(KBr,cm $\left.{ }^{-1}\right): 2212 v(\mathrm{CN}), 1680 v(\mathrm{C}=\mathrm{O})$, $1620 v(\mathrm{C}=\mathrm{N}), 1604(\mathrm{C}=\mathrm{C}) ; \mathrm{H}^{1} \mathrm{NMR}(400 \mathrm{MHz}, \mathrm{DMSO}-d 6): \delta=1.2-$ 1.37(t, 3H, $\left.\mathrm{CH}_{2} \mathrm{CH}_{3}\right)$; 4.1-4.23(q, $\left.2 \mathrm{H}, \mathrm{CH}_{2} \mathrm{CH}_{3}\right) ; 6.8-8.15(\mathrm{~m}, 7 \mathrm{H}$, $\mathrm{Ar}-\mathrm{H}, \mathrm{CH}=\mathrm{N})$; 8.51(s, $1 \mathrm{H}, \mathrm{C} 4-\mathrm{H}$ of coumarin); $\mathrm{MS}: \mathrm{M} / \mathrm{z}[\%]=$ 321(M+2, 2.6\%), 319(M+,37\%), 304(88\%), 290(26\%), 194(30 \%)Anal. calcd. for $\mathrm{C}_{18} \mathrm{H}_{13} \mathrm{~N}_{3} \mathrm{O}_{3}$ (319): C,67.71; H,4.10; N,13.16\%. Found: C,67.69; H,4.07; N,13.15\%.

\section{3-(4-aminopyrido[2,3-d]pyrimidin-7-yl)-2H-chromen-2-one (4).}

A mixture of 2 (2.3gm, 5mmol) and formamide $(10 \mathrm{ml})$ was boiled under reflux for $7 \mathrm{hrs}$. the reaction mixture was poured onto ice(30gm). The resulting solid was collected and recrystallized from acetic acid to give brown crystals. Yield: $62 \%$; mp.:>300 ${ }^{\circ} \mathrm{C}$; FT-IR $\left(\mathrm{KBr}, \mathrm{cm}^{-1}\right): 3413 v\left(\mathrm{NH}_{2}\right), 1682 v(\mathrm{C}=\mathrm{O}), \quad 1630$ $v(\mathrm{C}=\mathrm{N}), 1604(\mathrm{C}=\mathrm{C}) ; \mathrm{H}^{1} \mathrm{NMR}(400 \mathrm{MHz}, \mathrm{DMSO}-d 6): \delta=6.68(\mathrm{~s}$, $\left.2 \mathrm{H}, \mathrm{NH}_{2}\right) ; 7.5-8.11(\mathrm{~m}, 7 \mathrm{H}, \mathrm{Ar}-\mathrm{H}) ; 8.50(\mathrm{~s}, 1 \mathrm{H}, \mathrm{C} 4-\mathrm{H}$ of coumarin); MS: $\mathrm{M} / \mathrm{z}[\%]=290\left(\mathrm{M}^{+}, 27 \%\right), 274(8 \%), 190(16 \%), 169(31 \%)$;
130(83\%); 77(71\%); 51(65\%); Anal. calcd. for $\mathrm{C}_{16} \mathrm{H}_{10} \mathrm{~N}_{4} \mathrm{O}_{2}$ (290): C,66.20; H,3.47; N,19.30\%. Found: C,66.22; H,3.44; N,19.28\%.

\section{3-(3-amino-4-imino-3H,4H-pyrido[2,3-d]pyrimidin-7-yl)-2H- chromen-2-one(5).}

A mixture of 3 (1.6gm, 5mmol) and hydrazine hydrate ( $1 \mathrm{ml}, 20 \mathrm{mmol})$ was boiled under reflux for $3 \mathrm{hrs}$. in ethanol $(10 \mathrm{ml})$. The solid collected was crystallized from acetic acid to give5 as white crystals. Yield: $73 \%$; mp. :242-244 ${ }^{\circ} \mathrm{C}$; FT-IR $\left(\mathrm{KBr}, \mathrm{cm}^{-1}\right)$ : $3403 v$ (broad, $\left.\mathrm{NH}, \mathrm{NH}_{2}\right), 1678 v(\mathrm{C}=\mathrm{O}), 1620 v(\mathrm{C}=\mathrm{N}), 1604(\mathrm{C}=\mathrm{C})$; $\mathrm{H}^{1} \mathrm{NMR}(400 \mathrm{MHz}, \mathrm{DMSO}-d 6): \delta=6.8\left(\mathrm{~s}, 2 \mathrm{H}, \mathrm{NH}_{2}\right) ; 7.5-7.91(\mathrm{~m}$, $6 \mathrm{H}, \mathrm{Ar}-\mathrm{H}) ; 8.50(\mathrm{~s}, 1 \mathrm{H}, \mathrm{C} 4-\mathrm{H}$ of coumarin $) ; 9.52(\mathrm{~s}, 1 \mathrm{H}, \mathrm{CH}-$ pyrimidine); $11.0(\mathrm{~s}, 1 \mathrm{H}, \mathrm{NH}) ; \mathrm{MS}: \mathrm{M} / \mathrm{z}[\%]=307(\mathrm{M}+2,1.9 \%)$; 305( $\left.\mathrm{M}^{+}, 17 \%\right) ; 289(27 \%) ; 274(38 \%) ; 195(26 \%) ; 169(31 \%)$; 130(13\%); 77(77\%); 51(67\%); Anal. calcd. for $\mathrm{C}_{16} \mathrm{H}_{11} \mathrm{~N}_{5} \mathrm{O}_{2}(305)$ : C,62.95; H,3.63; N,22.94\%. Found: C,62.92; H,3.61; N,22.93\%.

\section{$N^{\prime}$-(3-cyano-6-(2-oxo-2H-chromen-3-yl)pyridin-2-yl)- $N, N$ - dimethylformamidine(6).}

A mixture of $2(2.6 \mathrm{gm}, 10 \mathrm{mmol})$ and DMFDMA(11.9gm, 14ml, 10mmol)in dry xylene $(20 \mathrm{ml})$ was refluxed for 4 hrs. the reaction mixture was cooled and the collected solid was washed with petroleum ether and recrystallized from Benzene to give 6 as Orange crystals. Yield: $94 \%$; mp. : $180-182^{\circ} \mathrm{C}$; FT$\mathrm{IR}\left(\mathrm{KBr}, \mathrm{cm}^{-1}\right): 3350 v(\mathrm{CH}$ aliphatc $), 2221 v(\mathrm{CN}) ; 1682 v(\mathrm{C}=\mathrm{O})$, $1617 v(\mathrm{C}=\mathrm{N}), 1604(\mathrm{C}=\mathrm{C}) ; \mathrm{H}^{1} \mathrm{NMR}(400 \mathrm{MHz}, \mathrm{DMSO}-d 6): \delta=$ $2.57\left(\mathrm{~s}, 6 \mathrm{H}, 2 \mathrm{CH}_{3}\right) ; 6.5(\mathrm{~s}, 1 \mathrm{H}, \mathrm{CH}=\mathrm{N}) ; 7.5-8.12(\mathrm{~m}, 6 \mathrm{H}, \mathrm{Ar}-\mathrm{H})$; 8.51(s, $1 \mathrm{H}, \mathrm{C} 4-\mathrm{H}$ of coumarin); MS: $\mathrm{M} / \mathrm{z}[\%]=320(\mathrm{M}+2,2.2 \%)$; $318\left(\mathrm{M}^{+}, 57 \%\right) ; 303(2.9 \%) ; 288(18 \%) ; 262(16 \%) ; 195(2 \%)$; 77(70\%); 51(77\%); Anal. calcd. for $\mathrm{C}_{18} \mathrm{H}_{14} \mathrm{~N}_{4} \mathrm{O}_{2}$ (318): C,67.91; $\mathrm{H}, 4.43$; N,17.60\%. Found: C,67.94; H,4.41; N,17.58\%.

\section{7-(2-oxo-2H-chromen-3-yl)pyrido[2,3-d]pyrimidin-4(3H)-one} (10)

A mixture of 2 (2.3gm, 5mmol) and formic acid $(10 \mathrm{ml})$ was boiled under reflux for $10 \mathrm{hrs}$. the reaction mixture was poured onto ice(30gm). The resulting solid was collected and recrystallized from ethanol to give yellow crystals. Yield: $82 \%$; mp. : $188-190^{\circ} \mathrm{C}, \quad \mathrm{FT}-\mathrm{IR}\left(\mathrm{KBr}, \mathrm{cm}^{-1}\right): 3340 v(\mathrm{NH}), \quad 1675,1690$ $v(\mathrm{C}=\mathrm{O}), 1630 v(\mathrm{C}=\mathrm{N}), 1614(\mathrm{C}=\mathrm{C}) ; \mathrm{H}^{1} \mathrm{NMR}$ (400MHz, DMSO$d 6): \delta=7.3-7.52(\mathrm{~m}, 6 \mathrm{H}, \mathrm{Ar}-\mathrm{H}) ; 8.52(\mathrm{~s}, 1 \mathrm{H}, \mathrm{C} 4-\mathrm{H}$ of coumarin); 9.29(s, 1H, pyrimidine); 11.12(s, 1H, NH); MS: M/z[\%]= 292 $(\mathrm{M}+1,17.2 \%) ; 291\left(\mathrm{M}^{+}, 18 \%\right), 169(3.1 \%) ; 130(83 \%) ; 77(51 \%)$; 51(55\%); Anal. calcd. for $\mathrm{C}_{16} \mathrm{H}_{9} \mathrm{~N}_{3} \mathrm{O}_{3}$ (291): C,65.98; H,3.11; $\mathrm{N}, 14.43 \%$. Found: C,65.97; H, 3.08; N,14.40\%.

\section{3-(4-chloropyrido[2,3-d]pyrimidin-7-yl)-2H-chromen-2-one(13).}

A mixture of $\mathbf{1 0}(2.9 \mathrm{gm}, 10 \mathrm{mmol})$ and phosphorus oxychloride $(20 \mathrm{ml})$ was heated under reflux for $5 \mathrm{hrs}$. the reaction mixture was cooled and poured onto ice(30gm). The resulting solid was collected and recrystallized from acetic acid to afford $\mathbf{1 3}$ as white crystals in a good yield. Yield: $74 \%$; mp. : 244$246^{\circ} \mathrm{C}, \mathrm{FT}-\mathrm{IR}\left(\mathrm{KBr}, \mathrm{cm}^{-1}\right): 1687 v(\mathrm{C}=\mathrm{O}), 1620 v(\mathrm{C}=\mathrm{N}), 1604(\mathrm{C}=\mathrm{C})$; $\mathrm{H}^{1} \mathrm{NMR}$ (400MHz, DMSO-d6): $\delta=7.32-7.61(\mathrm{~m}, 6 \mathrm{H}, \mathrm{Ar}-\mathrm{H})$; 
8.52(s, $1 \mathrm{H}, \mathrm{C} 4-\mathrm{H}$ of coumarin); $9.5(\mathrm{~s}, 1 \mathrm{H}$, pyrimidine $) ; \mathrm{MS}$ : $\mathrm{M} / \mathrm{z}[\%]=311(\mathrm{M}+2,32 \%) ; 309\left(\mathrm{M}^{+}, 29.7 \%\right) ; 274(17 \%) ; 169(52 \%)$; 130(13\%); 77(70\%); 51(15\%); Anal. calcd. for $\mathrm{C}_{16} \mathrm{H}_{8} \mathrm{ClN}_{3} \mathrm{O}_{2}$ (309): C,62.05; H,2.60; N,13.57\%. Found: C,62.07; H, 2.58; $\mathrm{N}, 13.54 \%$

\section{3-(4-hydazinylpyrido[2,3-d]pyrimidin-7-yl)-2H-chromen-2- one(14)}

A mixture of $\mathbf{1 3}(1.5 \mathrm{gm}, 5 \mathrm{mmol})$ and hydrazine hydrate $(1 \mathrm{gm}, 20 \mathrm{mmol})$ in ethanol $(10 \mathrm{ml})$ was heated under reflux for $3 \mathrm{hrs}$. the resulting solid was collected and recrystallized from acetic acid to give $\mathbf{1 4}$ as yellow crystals. Yield: 67\%; mp. : 281$283^{\circ} \mathrm{C}$; FT-IR $\left(\mathrm{KBr}, \mathrm{cm}^{-1}\right): 3409 v\left(\mathrm{NH}, \mathrm{NH}_{2}\right) ; 1687 v(\mathrm{C}=\mathrm{O}), 1630$ $v(\mathrm{C}=\mathrm{N}), 1617(\mathrm{C}=\mathrm{C}) ; \mathrm{H}^{1} \mathrm{NMR}(400 \mathrm{MHz}, \mathrm{DMSO}-d 6): \delta=6.8(\mathrm{~s}$, $\left.2 \mathrm{H}, \mathrm{NH}_{2}\right) ; 7.15-7.82(\mathrm{~m}, 6 \mathrm{H}, \mathrm{Ar}-\mathrm{H}) ; 8.50(\mathrm{~s}, 1 \mathrm{H}, \mathrm{C} 4-\mathrm{H}$ of coumarin); 9.51(s, $1 \mathrm{H}$, pyrimidine); $11.02(\mathrm{~s}, 1 \mathrm{H}, \mathrm{NH})$; MS: $\mathrm{M} / \mathrm{z}[\%]=307 \quad(\mathrm{M}+2, \quad 17 \%) ; \quad 305\left(\mathrm{M}^{+}, 29.7 \%\right) ; \quad 289(0.17 \%)$; 274(7.37); 186 (100\%); 174(14\%); 146(52\%); 97(18\%); 77(78\%); 50(54\%); Anal. calcd. for $\mathrm{C}_{16} \mathrm{H}_{11} \mathrm{~N}_{5} \mathrm{O}_{2}$ (305): C,62.95; H,3.63; N,22.94\%. Found: C,62.93; H, 3.60; N,22.92\%.

\section{3-(3,4,5,6,7,8,10-hexaazacyclopenta[a]naphthalene-11-yl)-2H- chromen-2-one (15)}

Saturated solution of sodium nitrite $(10 \mathrm{ml})$ was added while stirring to a cold solution at $0-5^{0} \mathrm{C}$ of $\mathbf{1 4}(1.7 \mathrm{gm}, 5 \mathrm{mmol})$ in acetic acid $(30 \mathrm{ml})$. The reaction mixture was stirred for $1 \mathrm{hr}$. the resulting solid was collected and recrystallized from acetic acid to give compound $\mathbf{1 5}$ as brown crystals. Yield: $85 \%$; mp.: $>300^{\circ} \mathrm{C}$; FT-IR $\left(\mathrm{KBr}, \mathrm{cm}^{-1}\right): 1690 v(\mathrm{C}=\mathrm{O}), 1636 v(\mathrm{C}=\mathrm{N}), 1607(\mathrm{C}=\mathrm{C}) ; \mathrm{H}^{1} \mathrm{NMR}$ (400MHz, DMSO- $d 6): \delta=7.35-7.9(\mathrm{~m}, 6 \mathrm{H}, \mathrm{Ar}-\mathrm{H}) ; 8.52(\mathrm{~s}, 1 \mathrm{H}, \mathrm{C} 4-$ $\mathrm{H}$ of coumarin); $9.25(\mathrm{~s}, 1 \mathrm{H}$, pyrimidine); MS: $\mathrm{M} / \mathrm{z}[\%]=$ $318(\mathrm{M}+2,1.8 \%) ; \quad 316\left(\mathrm{M}^{+}, 19.5 \%\right) ; \quad 170(57.6 \%) ; \quad 149(18 \%)$; 131(8.97\%); 91(41\%); 77(100\%); Anal. calcd. for $\mathrm{C}_{16} \mathrm{H}_{8} \mathrm{~N}_{6} \mathrm{O}_{2}$ (316): C,60.76; H,2.55; N,26.57\%. Found: C,60.74; H, 2.53; $\mathrm{N}, 26.55 \%$.

\section{2-(2-(4-bromophenyl)hydrazine-1-ylidene)-3-oxo-3-(2-oxo-2H- chromen-3-yl)propanal(16)}

A solution of $p$-bromobenzenediazonium chloride (5mmol) was added to a mixture of $\mathbf{1}(5 \mathrm{mmol})$, sodium acetate $(0.65 \mathrm{gm}, 5 \mathrm{mmol})$ in ethanol $(30 \mathrm{ml})$ at $0-5^{0} \mathrm{C}$ while stirring. The stirring was continued for $3 \mathrm{hrs}$. the resulting solid was collected, washed with water and recrystallized to give $\mathbf{1 6}$ as reddish brown crystals from acetic acid. Yield: $87 \%$; mp. : $284-286^{\circ} \mathrm{C}$, FT-IR $\left(\mathrm{KBr}, \mathrm{cm}^{-1}\right): 3352 v(\mathrm{NH}) ; 3060,2920 v(\mathrm{CH}$-aliphatic); 2866, $2754 v(\mathrm{CHO}) ; \quad 1715 v(\mathrm{C}=\mathrm{O}, \mathrm{CHO}) ; \quad 1678 v(\mathrm{broad}, \mathrm{C}=\mathrm{O}), 1636$ $v(\mathrm{C}=\mathrm{N}), 1604(\mathrm{C}=\mathrm{C}) ; \mathrm{H}^{1} \mathrm{NMR}(400 \mathrm{MHz}, \mathrm{DMSO}-d 6): \delta=7.47-$ 7.79(m, $8 \mathrm{H}, \mathrm{Ar}-\mathrm{H}) ; 8.52(\mathrm{~s}, 1 \mathrm{H}, \mathrm{C} 4-\mathrm{H}$ of coumarin); $8.81(\mathrm{~s}, 1 \mathrm{H}$, $\mathrm{NH}) ; \quad 13.59(\mathrm{~s}, 1 \mathrm{H}, \quad \mathrm{CHO}) ; \quad \mathrm{MS}: \quad \mathrm{M} / \mathrm{z}[\%]=398(\mathrm{M}+1,17 \%)$; 397( $\left.\mathrm{M}^{+}, 28 \%\right) ; 328(19.5 \%) ; 224(15.6 \%) ; 147(26.7 \%) ; 85(28.9 \%)$; Anal. calcd. for $\mathrm{C}_{18} \mathrm{H}_{11} \mathrm{BrN}_{2} \mathrm{O}_{4}$ (397): C,54.16; $\mathrm{H}, 2.78$; $\mathrm{N}, 7.02 \%$. Found: C,54.17; H, 2.76; N,6.99\%. 3-(3-(2-(4-bromophenyl) hydrazine -1 -ylidene)-3H-1,5benzodiazepin-2-yl)-2H- chromen-2-one(17), 4-(4-(2-(4bromophenyl)diazen-1-yl) -3-(2-oxo-2H -chromen-3-yl)-1Hpyrazol-1-yl) phenyl) azinic acid(18a), 2-(4-(2-(4-bromophenyl) diazen-1-yl)-3-(2-oxo-2H-chromen-3-yl)-1 $H$-pyrazol-1-yl)-5(hydroxynitroso)phenyl)azinic acid(18b).

\section{General Method}

A mixture of $16(5 \mathrm{mmol})$ and the appropriate of $o$ phenylenephenylenediamine, 4-nitrophenylhydrazine or 2,4dinitrophenylhydrazine $(5 \mathrm{mmol})$ in ethanol $(15 \mathrm{ml})$ was refluxed for $2 \mathrm{hrs}$. the resulting solid was collected and recrystallized from the proper solvent to give17,18a,b respectively.

\section{3-(3-(2-(4-bromophenyl)hydrazine-1-ylidene)-3H-1,5-} benzodiazepin-2-yl)-2H-chromen-2-one(17)

Yield: $92 \%$; mp. : $141-143^{\circ} \mathrm{C}, \mathrm{FT}-\mathrm{IR}\left(\mathrm{KBr}, \mathrm{cm}^{-1}\right)$ : $3352 v(\mathrm{NH}) ; 1680 v(\mathrm{C}=\mathrm{O}), 1616 v(\mathrm{C}=\mathrm{N}), 1600(\mathrm{C}=\mathrm{C}) ; \mathrm{H}^{1} \mathrm{NMR}$ (400MHz, DMSO- $d 6): \delta=6.85-7.66(\mathrm{~m}, 13 \mathrm{H}, \mathrm{Ar}-\mathrm{H}) ; 8.52(\mathrm{~s}, 1 \mathrm{H}$, $\mathrm{C} 4-\mathrm{H}$ of coumarin); $11.23(\mathrm{~s}, \quad 1 \mathrm{H}, \quad \mathrm{NH}) ; \quad \mathrm{MS}: \quad \mathrm{M} / \mathrm{z}[\%]=$ 472(M+2,87\%); 470( $\left.\mathrm{M}^{+}, 20 \%\right) ; 356(50 \%) ; 324(16 \%) ; 227(16 \%)$; 147(29\%); 77(90.23\%); Anal. calcd. for $\mathrm{C}_{24} \mathrm{H}_{15} \mathrm{BrN}_{4} \mathrm{O}_{2}$ (470): C,61.16; H,3.21; N,11.89\%. Found: C,61.18; H, 3.19; N,11.87\%.

\section{4-(4-(2-(4-bromophenyl)diazen-1-yl)-3-(2-oxo-2H-chromen-3-} yl)-1H-pyrazol-1-yl)phenyl)azinic acid(18a).

Yield: $\quad 78 \%$; $\quad \mathrm{mp} .: \quad 155-157^{\circ} \mathrm{C}, \mathrm{FT}-\mathrm{IR}\left(\mathrm{KBr}, \mathrm{cm}^{-1}\right)$ : $3305 v(\mathrm{CH}) ; 1694 v(\mathrm{C}=\mathrm{O}), 1616 v(\mathrm{C}=\mathrm{N}), 1596(\mathrm{C}=\mathrm{C}) ; \mathrm{H}^{1} \mathrm{NMR}$ (400MHz, DMSO- $d 6$ ): $\delta=7.18-7.8(\mathrm{~m}, 13 \mathrm{H}, \mathrm{Ar}-\mathrm{H}, \mathrm{CH}-$ pyrazole); $8.50(\mathrm{~s}, 1 \mathrm{H}, \mathrm{C} 4-\mathrm{H}$ of coumarin); MS: $\mathrm{M} / \mathrm{z}[\%]=517(\mathrm{M}+4 \%)$; 515( $\left.\mathrm{M}^{+}, 40 \%\right) ; \quad 470(15 \%) ; \quad 340(50 \%) ; \quad 314(10 \%) ; \quad 227(12 \%) ;$ $145(9 \%) ; 77(53 \%) ; 50(19 \%)$; Anal. calcd. for $\mathrm{C}_{24} \mathrm{H}_{14} \mathrm{BrN}_{5} \mathrm{O}_{4}$ (515): C,55.83; H,2.73; N,13.56\%. Found: C,55.85; H, 2.71; $\mathrm{N}, 13.53 \%$.

2-(4-(2-(4-bromophenyl)diazen-1-yl)-3-(2-oxo-2H-chromen-3yl)-1H-pyrazol-1-yl)-5-(hydroxynitroso)phenyl)azinic $\operatorname{acid}(\mathbf{1 8 b})$.

Yield: $\quad 84 \% ; \quad \mathrm{mp} .: 164-166^{\circ} \mathrm{C}, \mathrm{FT}-\mathrm{IR}\left(\mathrm{KBr}, \mathrm{cm}^{-1}\right): 1697$ $v(\mathrm{C}=\mathrm{O}), 1619 v(\mathrm{C}=\mathrm{N}), 1596(\mathrm{C}=\mathrm{C}) ; \mathrm{H}^{1} \mathrm{NMR}(400 \mathrm{MHz}, \mathrm{DMSO}-$ $d 6): \delta=7.18-8.12(\mathrm{~m}, 12 \mathrm{H}, \mathrm{Ar}-\mathrm{H}, \mathrm{CH}-\mathrm{pyrazole}) ; 8.50(\mathrm{~s}, 1 \mathrm{H}, \mathrm{C} 4-\mathrm{H}$ of coumarin); MS: $\mathrm{M} / \mathrm{z}[\%]=560\left(\mathrm{M}^{+}, 5 \%\right) ; 544(45 \%) ; 528(9 \%)$; 514(6\%); 446(50\%); 320(12\%); 127(8\%); 150(19\%); 77(902\%); 50(34\%)Anal. calcd. for $\mathrm{C}_{24} \mathrm{H}_{13} \mathrm{BrN}_{6} \mathrm{O}_{6}$ (560): C,51.36; H, 2.33; $\mathrm{N}, 14.97 \%$. Found: C,51.34; H, 2.30; N,14.95\%.

Ethyl -1-(4-chlorophenyl)-4-(2-oxo-2H-chromen-3-carbonyl)$1 H$-pyrazole-3-carboxylate(20a), Ethyl -1- (4-nitrophenyl)-4(2-oxo-2H-chromen-3-carbonyl)-1H-pyrazole-3-carboxylate (20b),3-(3-acetyl-1-(4-chlorophenyl)-1H-pyrazole- 4-carbonyl)$2 H$-chromen-2- one(20c), 3-(3-acetyl-1-(4-nitrophenyl)- $1 H$ pyrazole -4-carbonyl)-2H-chromen-2-one(20d). 


\section{General procedures}

A mixture of $\mathbf{1}$ (10mmol), the appropriate of hydrazonoyl halides (19a-d) $(10 \mathrm{mmol})$ and triethylamine $(1.5 \mathrm{ml}, 10 \mathrm{mmol})$ in dry benzene $(20 \mathrm{ml})$ was heated under reflux for $2 \mathrm{hrs}$. the reaction mixture evaporated under reduced pressure and triturated with petroleum ether 40/60. The resulting solid was collected and recrystallized from the proper solvent to give pyrazoles 20a-d in a good yield.

Ethyl -1-(4-chlorophenyl)-4-(2-oxo-2H-chromen-3-carbonyl)$1 H$-pyrazole-3-carboxylate (20a).

Beige crystals from ethanol.Yield: $92 \%$; mp. : 180$182^{\circ} \mathrm{C} ; \quad$ FT-IR $\left(\mathrm{KBr}, \mathrm{cm}^{-1}\right): \quad 3062 v(\mathrm{CH}), \quad 1666,1725 v(\mathrm{C}=\mathrm{O})$, $1630 v(\mathrm{C}=\mathrm{N}), \quad 1595(\mathrm{C}=\mathrm{C}) ; \mathrm{H}^{1} \mathrm{NMR} \quad(400 \mathrm{MHz}, \mathrm{DMSO}-d 6): \delta$ $=1.30\left(\mathrm{t}, 3 \mathrm{H}, \mathrm{CH}_{2} \mathrm{CH}_{3}\right)$; 4.5(q, 2H, $\left.\mathrm{CH}_{2} \mathrm{CH}_{3}\right)$, 7.5-8.2 (m, 9H, Ar-H, $\mathrm{CH}-$ pyrazole); $8.52(\mathrm{~s}, 1 \mathrm{H}, \mathrm{C} 4-\mathrm{H}$ of coumarin); $\mathrm{MS}: \mathrm{M} / \mathrm{z}[\%]=$ 424(M+2,14\%); 422( $\left.\mathrm{M}^{+}, 10 \%\right) ; 407(8 \%) ; 393(15 \%) ; 359(54 \%)$; $343(15 \%) ; 272(21 \%) ; 201(17 \%) ; 147(29 \%) ; 77(90 \%) ; 74(54 \%)$; Anal. calcd. for $\mathrm{C}_{22} \mathrm{H}_{15} \mathrm{ClN}_{2} \mathrm{O}_{5}$ (422): C,62.49; H, 3.58; N,6.63\%. Found: C,62.47; H, 3.55; N,6.60\%.

Ethyl -1-(4-nitrophenyl)-4-(2-oxo-2H-chromen-3-carbonyl)$1 H$-pyrazole-3-carboxylate (20b).

Beige crystals from ethanol. Yield: 89\%; mp. : 149$151^{\circ} \mathrm{C}$; FT-IR $\left(\mathrm{KBr}, \mathrm{cm}^{-1}\right): 3030 v(\mathrm{CH}), 1670,1720 v(\mathrm{C}=\mathrm{O}), 1618 v$ $(\mathrm{C}=\mathrm{N}), 1595(\mathrm{C}=\mathrm{C}) ; \mathrm{H}^{1} \mathrm{NMR}(400 \mathrm{MHz}, \mathrm{DMSO}-d 6): \delta=1.32(\mathrm{t}, 3 \mathrm{H}$, $\mathrm{CH}_{2} \mathrm{CH}_{3}$ ); 4.23(q, 2H, $\mathrm{CH}_{2} \mathrm{CH}_{3}$ ), 7.35-8.1 (m, 8H, Ar-H); 8.23(s, $1 \mathrm{H}, \mathrm{CH}$-pyrazole $\mathrm{H}-5)$; $8.50(\mathrm{~s}, 1 \mathrm{H}, \mathrm{C} 4-\mathrm{H}$ of coumarin); Anal. calcd. for $\mathrm{C}_{22} \mathrm{H}_{15} \mathrm{~N}_{3} \mathrm{O}_{7}$ (433): C,60.97; H, 3.49; N,9.70\%. Found: C,60.96; H, 3.46; N,9.68\%.

\section{3-(3-acetyl-1-(4-chlorophenyl)-1H-pyrazole-4-carbonyl)-2H-} chromen-2-one(20c).

Yellow crystals from Dioxane. Yield: 91\%; mp.:162$164^{\circ} \mathrm{C}$; FT-IR $\left(\mathrm{KBr}, \mathrm{cm}^{-1}\right): 1666,1680 v($ broad, $\mathrm{C}=\mathrm{O}), 1640 v(\mathrm{C}=\mathrm{N})$, 1600 $(\mathrm{C}=\mathrm{C}) ; \mathrm{H}^{1} \mathrm{NMR}(400 \mathrm{MHz}, \mathrm{DMSO}-d 6): \delta=2.5\left(\mathrm{~s}, 3 \mathrm{H}, \mathrm{CH}_{3}\right)$; 7.11-7.92 (m, 9H, Ar-H, CH-pyrazole H-5); 8.52(s, 1H, C4-H of coumarin); $\mathrm{MS}: \mathrm{M} / \mathrm{z}[\%]=393(\mathrm{M}+1,60 \%) ; \quad 392\left(\mathrm{M}^{+}, 45 \%\right)$; $377(1.5 \%) ; \quad 342(9 \%) ; \quad 327(51 \%) ; \quad 227(16 \%) ; \quad 171(16 \%)$; 146(2.9\%); 77(91\%); Anal. calcd. for $\mathrm{C}_{21} \mathrm{H}_{13} \mathrm{ClN}_{2} \mathrm{O}_{4}$ (392): $\mathrm{C}$, 64.21; H,3.34; N,7.13\%. Found: C,64.23; H, 3.31; N,7.11\%.

\section{3-(3-acetyl-1-(4-nitrophenyl)-1H-pyrazole-4-carbonyl)-2H- chromen-2-one(20d).}

Yellow crystals from ethanol. Yield: 89\%; mp.: 171$173^{\circ} \mathrm{C}$; FT-IR(KBr,cm $\left.{ }^{-1}\right): 1666,1680 v($ broad, $\mathrm{C}=\mathrm{O}), 1640 v(\mathrm{C}=\mathrm{N})$, 1604(C=C); $\mathrm{H}^{1} \mathrm{NMR}(400 \mathrm{MHz}, \mathrm{DMSO}-d 6): \delta=2.53\left(\mathrm{~s}, 3 \mathrm{H}, \mathrm{CH}_{3}\right)$; 7.11-7.92 (m, 9H, Ar-H, CH-pyrazole H-5); 8.52(s, 1H, C4-H of coumarin); Anal. calcd. for $\mathrm{C}_{21} \mathrm{H}_{13} \mathrm{~N}_{3} \mathrm{O}_{6}$ (403): C,62.53; H,3.25; $\mathrm{N}, 10.42 \%$. Found: C,62.55; H, 3.23; N, $10.40 \%$.

3-(2-(4-chlorophenyl)-7-hydroxy-2H-pyrazolo[3,4-d]pyridazin4-yl)-2H-chromen-2-one(21a), 3-(2-(4-nitrophenyl)-7-hydroxy-
2H-pyrazolo[3,4- $d]$ pyridazin-4-yl)-2H-chromen-2-one(21b), 3(2-(4-chlorophenyl)-7-methyl-2H-pyrazolo[3,4- $d]$ pyridazin-4yl)-2H-chromen-2-one(21c), 3-(2-(4-nitrophenyl)-7-methyl-2Hpyrazolo[3,4-d]pyridazin-4-yl)-2H-chromen-2-one(21d).

\section{General procedures}

A mixture of the appropriate pyrazoles $20 \mathrm{a}-\mathrm{d}(5 \mathrm{mmol})$ and hydrazine hydrate $(1 \mathrm{gm}, 1 \mathrm{ml}, 10 \mathrm{mmol})$ in ethanol $(10 \mathrm{ml})$ was heated under reflux for 3 hrs. the reaction mixture was cooled and the resulting solid was collected and recrystallized from the proper solvent to give pyrazolo[3,4-d]pyridazines 21a-d, respectively.

\section{3-(2-(4-chlorophenyl)-7-hydroxy-2H-pyrazolo[3,4-d]pyridazin-} 4-yl)-2H-chromen-2-one(21a).

White crystals from ethanol. Yield: 69\%; mp. :>300 ${ }^{\circ} \mathrm{C}, \mathrm{FT}-\mathrm{IR}\left(\mathrm{KBr}, \mathrm{cm}^{-1}\right): \quad 3450 v(\mathrm{OH}) ; \quad 1680 \quad v(\mathrm{C}=\mathrm{O})$, $1635 v(\mathrm{C}=\mathrm{N}), \quad 1604(\mathrm{C}=\mathrm{C}) ; \mathrm{H}^{1} \mathrm{NMR} \quad(400 \mathrm{MHz}, \mathrm{DMSO}-d 6): \delta=$ 7.32-7.81 (m, 8H, Ar-H); 8.12(s, 1H, CH-pyrazole); 8.52(s, 1H, C4-H of coumarin); 9.42(s, 1H, OH); MS: M/z[\%]= 391(M+1, $1 \%)$; 390( $\left.\mathrm{M}^{+}, 14 \%\right) ; 374(3 \%) ; 201(50 \%) ; 178(16 \%) ; 165(16 \%)$; 143(29\%); 77(90.23\%); 50(18\%); Anal. calcd. for $\mathrm{C}_{20} \mathrm{H}_{11} \mathrm{ClN}_{4} \mathrm{O}_{3}(390)$ : C,61.47; H,2.84; N,14.34\%. Found: C,61.44; $\mathrm{H}, 2.82 ; \mathrm{N}, 14.33 \%$.

\section{3-(2-(4-nitrophenyl)-7-hydroxy-2H-pyrazolo[3,4-d]pyridazin- 4-yl)-2H-chromen-2-one(21b).}

White crystals from ethanol. Yield: $82 \%$; mp. : 291$293^{\circ} \mathrm{C}$; FT-IR $\left(\mathrm{KBr}, \mathrm{cm}^{-1}\right): 3460 v(\mathrm{OH}) ; 1686 v(\mathrm{C}=\mathrm{O}), 1635 v(\mathrm{C}=\mathrm{N})$, 1614(C=C); $\mathrm{H}^{1} \mathrm{NMR}(400 \mathrm{MHz}, \mathrm{DMSO}-d 6): \delta=7.32-7.81(\mathrm{~m}, 8 \mathrm{H}$, Ar-H); 8.23(s, 1H, CH-pyrazole); $8.50(\mathrm{~s}, 1 \mathrm{H}, \mathrm{C} 4-\mathrm{H}$ of coumarin); 9.51(s, 1H, OH); Anal. calcd. for $\mathrm{C}_{20} \mathrm{H}_{11} \mathrm{~N}_{5} \mathrm{O}_{5}$ (401): C,59.85; H,2.76; N,17.45\%. Found: C,59.83; H, 22.75; N,17.42\%.

\section{3-(2-(4-chlorophenyl)-7-methyl-2H-pyrazolo[3,4-d]pyridazin- 4-yl)-2H-chromen-2-one(21c).}

Beige crystals from ethanol. Yield: $85 \%$; mp.: $>300^{\circ} \mathrm{C}$; FT-IR $\left(\mathrm{KBr}, \mathrm{cm}^{-1}\right): \quad 1690 \quad v(\mathrm{C}=\mathrm{O}), \quad 1635 v(\mathrm{C}=\mathrm{N}), \quad 1600(\mathrm{C}=\mathrm{C})$; $\mathrm{H}^{1} \mathrm{NMR}(400 \mathrm{MHz}, \mathrm{DMSO}-d 6): \delta=2.57\left(\mathrm{~s}, 3 \mathrm{H}, \mathrm{CH}_{3}\right) ; 7.12-8.14(\mathrm{~m}$, 9H, Ar-H, CH-pyrazole); 8.52(s, 1H, C4-H of coumarin); MS: $\mathrm{M} / \mathrm{z}[\%]=389(\mathrm{M}+1,15 \%) ; 388\left(\mathrm{M}^{+}, 27 \%\right) ; 373(10 \%) ; 338(12 \%)$; 327(16\%); 227(16\%); 91(2.9\%); 77(93\%); 50(5\%); Anal. calcd. for $\mathrm{C}_{21} \mathrm{H}_{13} \mathrm{ClN}_{4} \mathrm{O}_{2}(388)$ : $\mathrm{C}, 64.87 ; \mathrm{H}, 3.37 ; \mathrm{N}, 14.41 \%$. Found: C,64.88; H, 3.34; N,14.39\%.

\section{3-(2-(4-nitrophenyl)-7-methyl-2H-pyrazolo[3,4-d]pyridazin-4-} yl)-2H-chromen-2-one(21d).

Beige crystals from ethanol. Yield: $81 \%$; mp.:>300 ${ }^{\circ}$; FT-IR $\left(\mathrm{KBr}, \mathrm{cm}^{-1}\right): \quad 1689 v(\mathrm{C}=\mathrm{O}), \quad 1640 v(\mathrm{C}=\mathrm{N}), \quad 1600(\mathrm{C}=\mathrm{C})$; $\mathrm{H}^{1} \mathrm{NMR}(400 \mathrm{MHz}, \mathrm{DMSO}-d 6): \delta=2.57\left(\mathrm{~s}, 3 \mathrm{H}, \mathrm{CH}_{3}\right) ; 7.32-7.84(\mathrm{~m}$, $8 \mathrm{H}, \mathrm{Ar}-\mathrm{H}), 8.14(\mathrm{~s}, 1 \mathrm{H}, \mathrm{CH}-$ pyrazole); 8.53(s, 1H, $\mathrm{C} 4-\mathrm{H}$ of coumarin); Anal. calcd. for $\mathrm{C}_{21} \mathrm{H}_{13} \mathrm{~N}_{5} \mathrm{O}_{4}(399)$ : C,63.16; H,3.28; $\mathrm{N}, 17.54 \%$. Found: C,63.13; H, 3.26; N,17.53\%. 


\section{PHARMACOLOGY}

\section{Antimicrobial activity}

The samples were prepared by dissolving $2 \mathrm{mg}$ in $2 \mathrm{ml}$ of DMSO and $100 \mu \mathrm{l}$ (containing $100 \mu \mathrm{g}$ ) was used in this test. The antimicrobial activity of different samples was investigated by the agar cup plate method. Four different test microbes namely: Staphylococcus aureus (G+ve), Pseudomonas aeruginosa (G-ve), Candida albicans (yeast) and Aspergillus niger (fungus) were used. Nutrient agar plates were heavily seeded uniformly with $1 \mathrm{ml}$ of $10^{5}-10^{6}$ cells $/ \mathrm{ml}$ in case of bacteria and yeast. A Czapek-Dox agar plate seeded by the fungus was used to evaluate the antifungal activities. Then a hole was made in media by gel cutter (Cork borer no.4) in sterile condition. Then one drop of melted agar was poured into hole and allowed to solidify to make a base layer. After that specific amount of culture filtrate $(0.1 \mathrm{ml})$ was poured into the hole. Then plates were kept at low temperature $\left(4^{\circ} \mathrm{C}\right)$ for 2-4 hours to allow maximum diffusion. The plates were then incubated at $37{ }^{\circ} \mathrm{C}$ for 24 hours for bacteria and at $30{ }^{\circ} \mathrm{C}$ for 48 hours in upright position to allow maximum growth of the organisms. The antimicrobial activity of the test agent was determined by measuring the diameter of zone of inhibition expressed in millimeter $(\mathrm{mm})$. The experiment was carried out more than once and mean of reading was recorded (Abdel-Aziz et al., 2014; Barry, 1976).

\section{Antioxidant screening assay using DPPH radical scavenging ability}

Sigma-Aldrich

$$
\text { 2,2-diphenyl-1-picrylhydrazyl radical (DPPH) }
$$

\section{DPPH radical scavenging ability}

Samples $(100 \mu \mathrm{l})$ from stock solution of concentration $1 \mathrm{mg} / \mathrm{ml}$ in DMF were mixed with $900 \mu \mathrm{l}$ of $0.1 \mathrm{mM}$ DPPH solution in methanol. The mixture was shaken vigorously and allowed to reach a steady state at temperature $37^{\circ} \mathrm{c}$ for $30 \mathrm{~min}$. Decolurization of DPPH was determined by measuring the absorbance at $517 \mathrm{~nm}$, and the DPPH radical scavenging was calculated according to the following equation:

$\%$ scavenging rate $=\left(\mathrm{A}_{1}-\mathrm{A}_{2} / \mathrm{A}_{1}\right) \times 100$

Where $A_{1}$ was the absorbance of the DPPH solution without test sample and $\mathrm{A}_{2}$ was the absorbance of DDPH with the test sample. Ascorbic acid was taken as the standard.

\section{Cytotoxicity evaluation}

Vero cells obtained from adult African green monkey kidney epithelial cells according to American Type Culture Collection (ATCC) and the European Collection of Animal Cell Cultures (ECACC) repositories No.CCL-81, passage number: 136, kindly obtained from VACSERA, Egypt. Vero cell line was grown in liquid growth medium of Dulbecco's modification of Eagle medium (Silva et al., 2008). Vero cells were stored in liquid nitrogen vapor phase and cells usually take 2-3 passages to reach their regular growth rate after recovery from frozen state (Phelan,
2007). Dulbecco's modification of Eagle medium (MEM) with fetal bovine serum (FBS), Antibiotic (penicillin/streptomycin) fungizone solution (LONZA), 4-(2-hydroxyethyl)-1piperazineethanesulfonic acid (HEPES) buffer $1 \mathrm{M} \mathrm{pH}$ values ranging from 6.8 - 8.2 (LONZA), Earle's salt and L-glutamine, sterile polystyrene $75 \mathrm{~cm}^{2}$ tissue culture flasks with vented caps, sterile serological pipettes and $70 \%$ ethanol solution, all to be used in cell propagation. Equipment and solutions coming into contact with cells have been sterile, and proper sterile techniques were used. i.e, $70 \%$ ethanol used for decontamination of laminar flow hood and objects brought into the hood, $\mathrm{CO}_{2}$ Incubator interior, inverted microscope cleaning of objectives and stage daily. Cell culture incubations were in a $37{ }^{\circ} \mathrm{C}$ humidified incubator and solutions were wormed to $37{ }^{\circ} \mathrm{C}$ just before headway (Suffness et al., 1990; Himmel, 2015).

In a laminar flow hood, Vero cell suspension from the cryovial was transferred into a $75 \mathrm{~cm}^{2}$ tissue culture flasks containing $25 \mathrm{~mL}$ growth medium (GM) of MEM supplemented with heat inactivated $10 \%$ FBS, $1 \%$ HEPES and $1 \%$ antibiotic, A cryovial of Vero cells containing $1 \times 106$ cells/1ml was thawed by gently swirling in a $37{ }^{\circ} \mathrm{C}$ water bath for 2 minutes and added to incubated flask in $37^{\circ} \mathrm{C}$, Vero cells grown to a $90-95 \%$ confluency in a $75 \mathrm{~cm}^{2}$ flask, Growth medium from confluent monolayer of Vero cells was removed and cells washed with 1x PBS twice, $5 \mathrm{~mL}$ of $1 \mathrm{X}$ trypsin-EDTA added and cells were incubated at $37^{\circ} \mathrm{C}$ for 23 minutes, until cells detached from the flask, 50ml GM was added. Divide it into 2 flasks each containing 25ml. Flasks incubated at $37^{\circ} \mathrm{C}$. Cells checked for confluency using inverted microscope. When cells reached a $>90 \%$ confluent monolayer, cells were passaged at suitable concentration of cells needed (30.000cells/100ul/well).

Samples were diluted in $100 \mu \mathrm{l}$ Maintenance media (MM) as $2 \%$ FBS, 1\% HEPES, 1\% antibiotic, and $96 \%$ MEM Earle's and the used dilutions were $100 \mu \mathrm{g}, 50 \mu \mathrm{g}$ and $10 \mu \mathrm{g}$ per well in triples in 96 well plate. Cell then added in each well and mixed well to be sure of its homogeneity. Plate were covered with sealing and incubated at $37^{\circ} \mathrm{c}$ overnight in $\mathrm{Co}_{2}$ incubator, plate has been checked under inverted microscope and wells were washed with PBS twice to be ready for staining with crystal violet stain $(0.5 \%$ crystal violet, $5 \%$ formalin, $50 \%$ ethanol, $\left.0.85 \% \mathrm{NaCl}, \mathrm{H}_{2} \mathrm{O}\right) 10 \mu \mathrm{l}$ for 10 minutes followed by washing with distal $\mathrm{H}_{2} \mathrm{O}$ three times and let it to dry and measure the plate readings in ELISA plate reader at wave length $630 \mathrm{~nm}$ (Himmel, 2015; Ouattara et al., 2011; Baudoin et al., 2007).

\section{RESULTS AND DISCUSSION}

\section{Chemistry}

The synthetic procedures adopted to obtain the target compound 1 were previously reported (Abdel-Rahman et al., 2003) to be synthesized through refluxing of 3-acetyl- $2 H$ chromen-2-one with dimethylformamide-dimethyl acetal (DMFDMA) (Al-Zaydi, 2003). The starting compound $\mathbf{2}$ was synthesized through the reaction of $\mathbf{1}$ with malononitrile in acetic acid in the presence of catalytic amount of ammonium acetate. The 
newly synthesized aminocyanopyridine derivative $\mathbf{2}$ has now estimated as key molecule for synthesis of new 3-substituted coumarinheterocyclic compounds through the consideration reaction of compound $\mathbf{2}$ with triethylorthoformate and formamide to give compounds $\mathbf{3}$ and $\mathbf{4}$, respectively. Structure of $\mathbf{3}$ was confirmed by spectral data (IR, $\mathrm{H}^{1} \mathrm{NMR}$, mass spectrometry and elemental analysis). Its IR spectrum devoid any bands for $\mathrm{NH}_{2}$ group which indicated its participation in the reaction and showed a strong absorption band at 2212 attributed to $v$ of $\mathrm{CN}$ group.Also, the $\mathrm{H}^{1} \mathrm{NMR}$ spectrum of compound 3 showed triplet signal at 1.2$1.37 \mathrm{ppm}$ for three protons of methyl group of $\mathrm{CH}_{2} \mathbf{C H}_{3}$ group and showed quartet signal at 4.1-4.23ppm for two protons of $\mathrm{CH}_{2}$ group of $\mathbf{C H}_{2} \mathrm{CH}_{3}$. In addition, the structure of compound $\mathbf{3}$ was inferred chemically, in which it reacted with the nucleophile hydrazine hydrate to give the target molecule substituted3-amino4-imino-pyridopyrimidine5. Compound $\mathbf{5}$ can be obtained via alternative synthetic pathway, in which the reaction of $\mathbf{2}$ with dimethylformamide-dimethylacetal in dry dioxane give compound 6 which further reacted with hydrazine hydrate to give a product identical in all aspects (m.p. and mixed m.p., IR, $\mathrm{H}^{1} \mathrm{NMR}$, mass spectrum and elemental analysis) with compound $\mathbf{5}$ that obtained from the previous method (Scheme 1).<smiles>[R]c1ccc(C#N)c(N)n1</smiles>

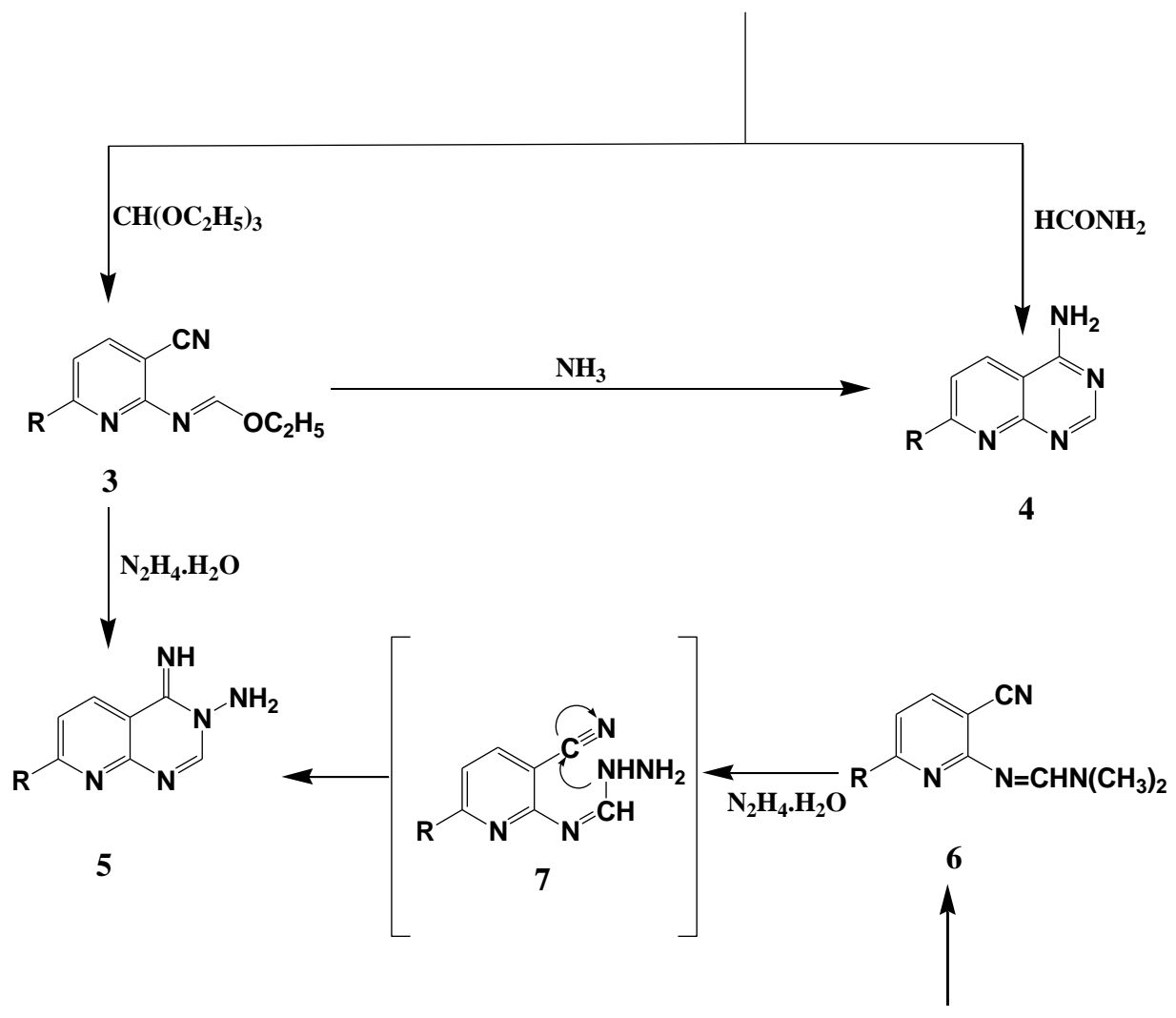

2 + DMF-DMA

\section{Scheme 1}




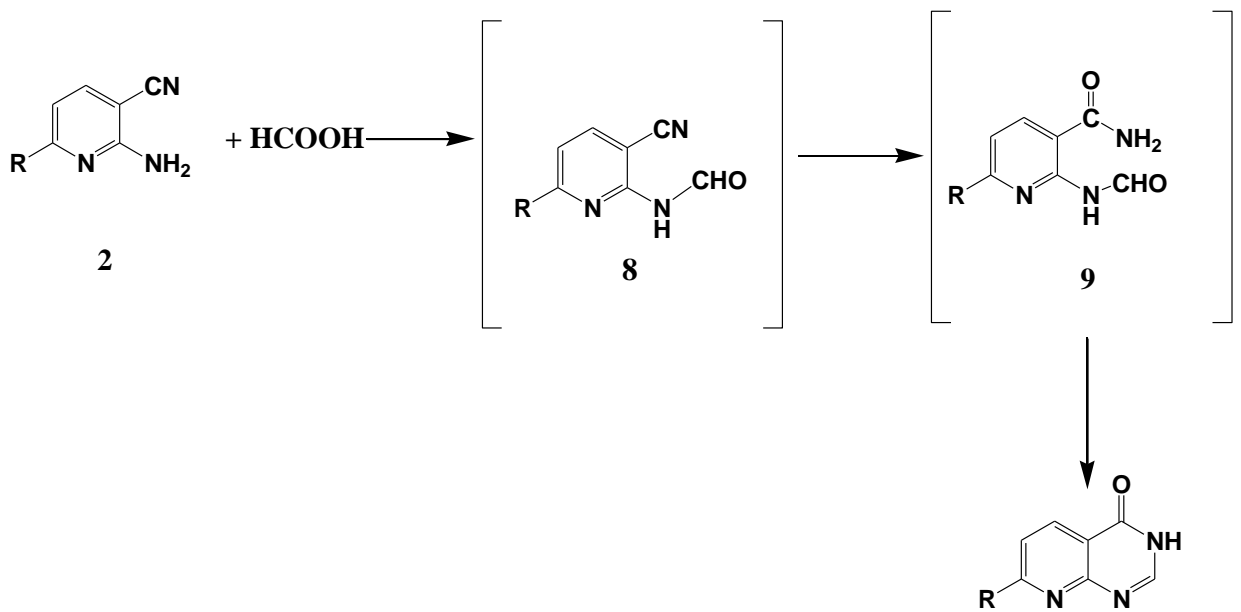

Scheme 2

10

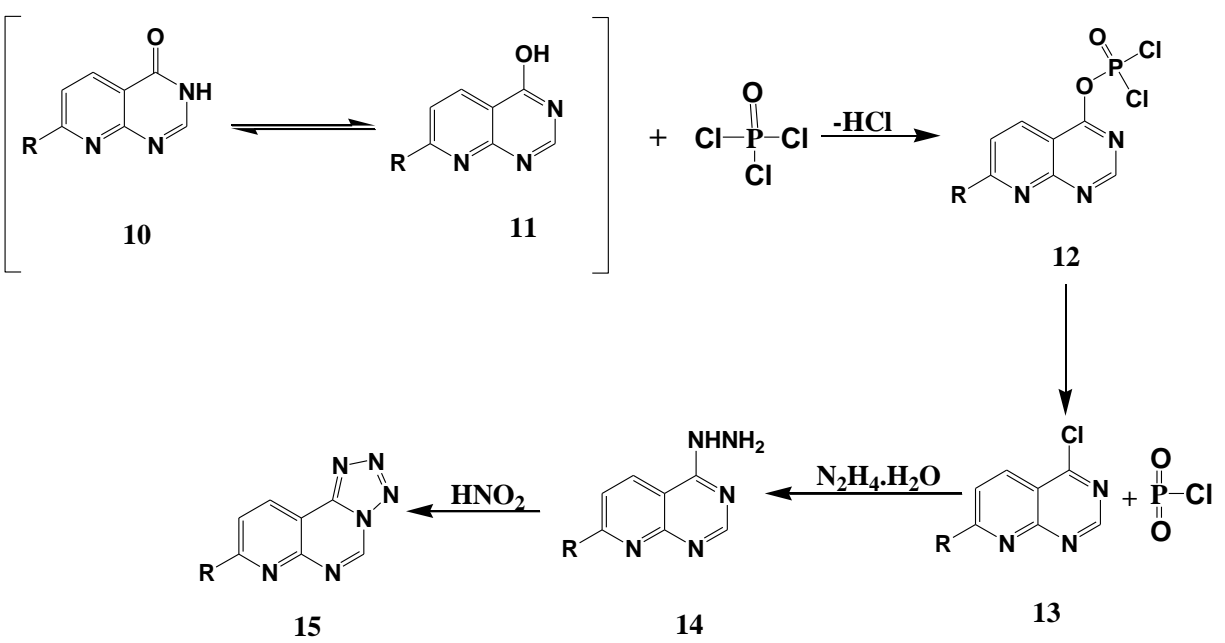

Scheme 3

Cyclocondensation reaction of $\mathbf{2}$ with formic acid give pyrimidinone fused derivative $\mathbf{1 0}$ (Scheme 2). The reaction was carried out thermally in absence of solvent. The reaction proceeded through hydration of nitrile group to carboximide which then submitted to cyclization reaction to yield the compound $\mathbf{1 0}$. The structure of $\mathbf{1 0}$ was investigated from its IR, $\mathrm{H}^{1} \mathrm{NMR}$, mass spectrometry and microanalysis.

The spectral data revealed the disappearance of $\mathrm{CN}, \mathrm{NH}_{2}$ groups indicating their involvement in the cyclization process. The IR spectra of $\mathbf{1 0}$ showed also two strong absorption bands at the regions 1675, 1690 attributed to $v$ max of two carbonyl groups which indicated the formation of new carbonylgroup due to the formation of pyrimidinone fused ring system in addition to the carbonyl group of coumarin ring system.
Formation of compound $\mathbf{1 0}$ is thought to take place through expected intermediates which are not isolated. Also, the $\mathrm{H}^{1} \mathrm{NMR}$ spectrum showed singlet signal at $9.29 \mathrm{ppm}$.attributed to the proton of pyrimidinone ring (Scheme 2).

The structure of $\mathbf{1 0}$ was verified chemically through its reaction with phosphorus oxychlorideto yield the corresponding chloro-derivative 13, an internal nucleophilic substitution reaction by chloride ion on the carbon ion of lactim form 12 occurred (SNi mechanism). The structure of $\mathbf{1 3}$ was inferred from its spectral data in which its IR spectrum devoid any bands for $\mathrm{C}=\mathrm{O}$ group. Compound 13 was submitted to react with hydrazine hydrate to give the hydrazide14. The latter was converted to $\mathbf{1 5}$ via its reaction with nitrous acid at $0-5^{\circ} \mathrm{C}$ through diazotization of the hydrazide derivative 14 (Scheme 3). 
Treatment of enamine 1 with $p$-bromobenzenediazonium chloride in ethanol containing sodium acetate as abuffer solution yielded 16. The structure of $\mathbf{1 6}$ was elucidated chemically via its reaction with $o$-phenylenediamine, 4-nitrophenylhydrazine and 2,4dinitrophenylhydrazineto give the corresponding derivatives 17, 18a and 18b respectively( Scheme 4). When enamine 1 was submitted to react with the appropriate hydrazonoyl halide 19a-d in dry benzene in the presence of catalytic amount of triethylamine under reflux it give the corresponding substituted pyrazoles 20a-d. Structures of compounds 20a-d were confirmed via chemical transformationin which they reacted with hydrazine hydrate to give the corresponding pyrazolo[3,4- $d]$ pyradazines21ad,respectively (Scheme 5) which indicated the formation of 20a-d and not 22a-d.

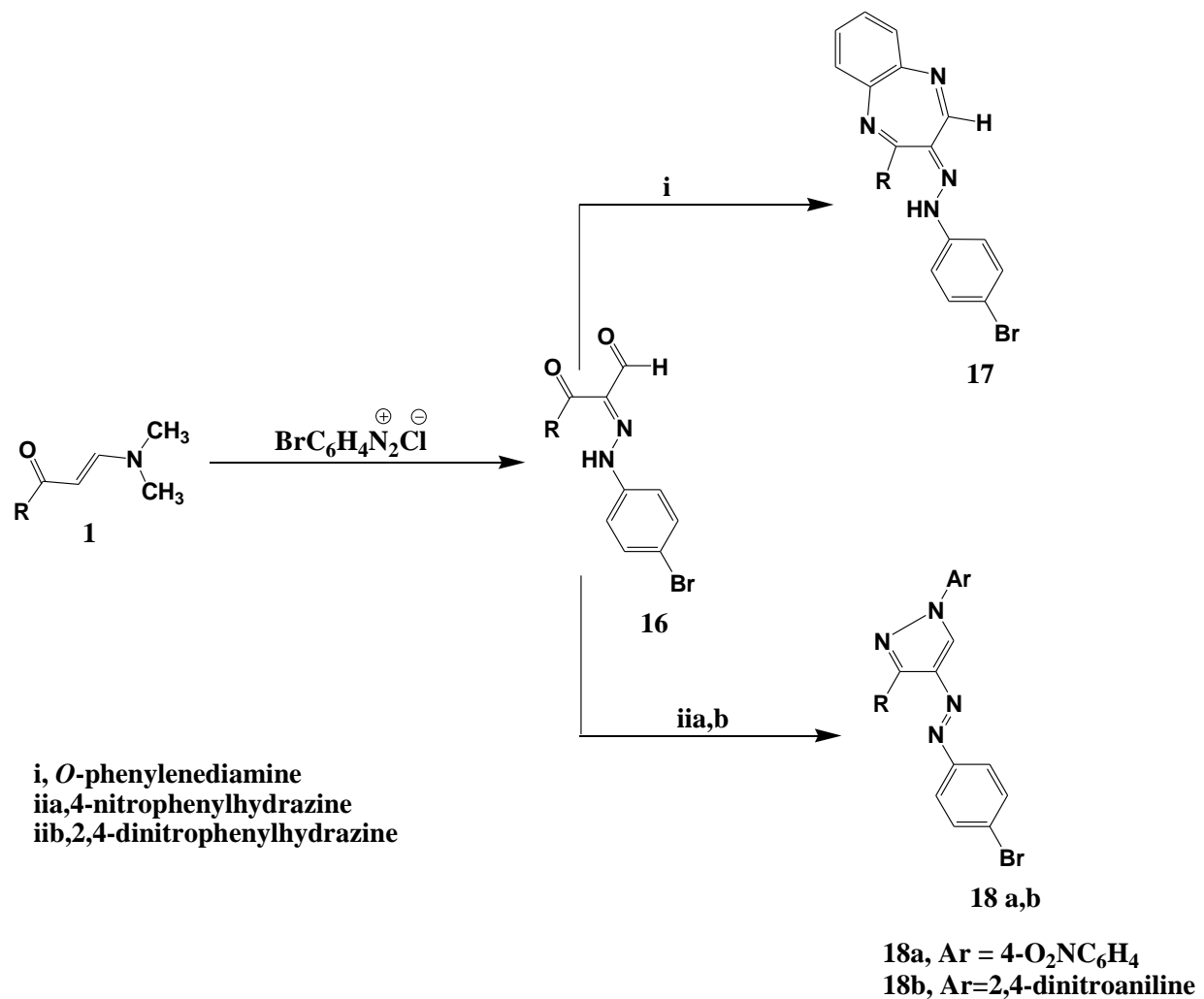

Scheme 4

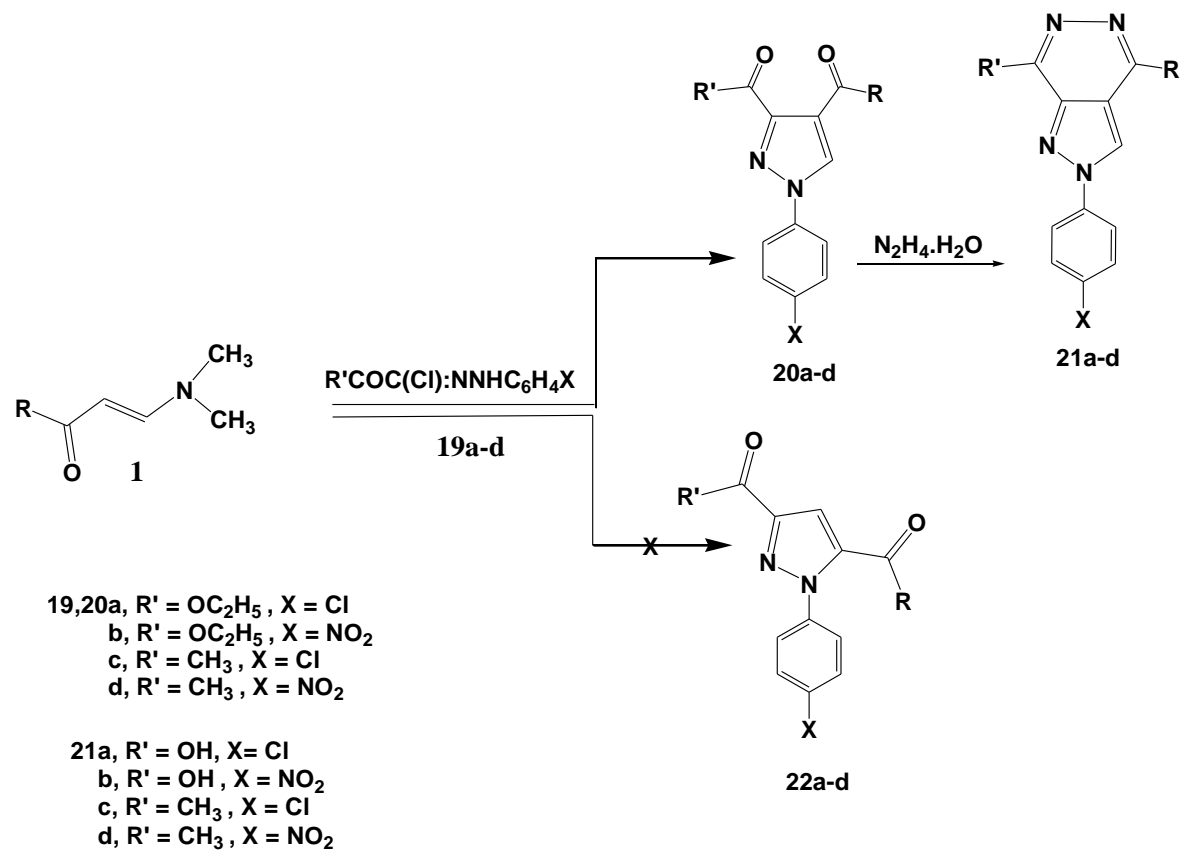

Scheme 5 


\section{PHARMACOLOGY}

\section{Antimicrobial activity}

Resistance to antibiotic is a developing and serious problem, has become an increasingly important and pressing global problem. In communities and hospitals around the world, the number of patients with antibiotic-resistant infections continues to rise. The reasons of antimicrobial resistance are multifactorial. Some of this is due to the overuse of antibiotics in human (Panlilio et al., 1992) and hence microbes intrinsically resist antimicrobials or have acquired resistance mechanism to these substances (Hassan et al., 1999; Lerner ,1998). So, there is an urgent demand for discover new antibiotics.

The newly synthesized 3-substituted coumarin derivatives were evaluated for their in vitro antimicrobial potentiality against four microbial strains, namely: Staphylococcus aureus (G+ve), Pseudomonas aeruginosa (G-ve), Candida albicans (yeast) and Aspergillus niger (fungus). Neomycin was used as standard antibacterial agent whereas Cycloheximide was used as anti-fungal agent to compare the effect of the tested compounds under the same condition. Results in Table (1) illustrate the antimicrobial activities of different coumarin derivatives. It has been found that compound $20 \mathbf{b}$ have the strongest antibacterial activity against the $\mathrm{G}+\mathrm{ve}$ bacterium Staphylococus aureus (25mm) as compared to the standard drug (Neomycin) and the other tested compounds. On basis of structure activity relationship (SAR) this strong effect of compound 20b may be due to the presence of ester and nitro groups attached to the pyrazole ring. Also, compounds 18b, 20c and 20d exhibited high antibacterial activity against $S$. aureus $(20,18$ and $17 \mathrm{~mm}$, respectively). Whereas, compounds 17,10,5 and 2 exhibited an equal clear zone values $(15 \mathrm{~mm})$. The antibacterial activity of the tested compounds toward the G-ve test, Pseudomonas aeruginosahas been explored. The highest inhibitory effect was noticed with compounds 2,21d, 10,18b, 3 and 20b(20, 20, 19, 19, 18 and $18 \mathrm{~mm}$, respectively). Moderate antibacterial activity against $P$. aeruginosa has been reported with the compounds 5, 17, 20c, 18a, 20d, 14 and 21b with clear zones of 17, 17, 15, 15, 15, 14 and $16 \mathrm{~mm}$ respectively. Lower activity was reported with compound $2 \mathbf{a}(12 \mathrm{~mm})$. Concerning the effect of the synthesized coumarin derivatives on the pathogenic yeast test strain Candida albicans, it has been found that compounds 18b, 2, 21d, 3, 5, 10, 17 and 20c exhibited higher antimicrobial activity against $C$. albicans (20, 19, 19, 18, 18, 18,18 and 18mm, respectively). Compound 18a showed moderate activity (14mm), whereas compounds, 20d,13 and 14 showed lower activity (12, 13 and $13 \mathrm{~mm}$, respectively). The synthesized coumarin derivatives were also tested as antifungal agents using Aspergillus niger. Compounds 20b,3, 20d, 20cand18aexhibited high antifungal activity $(32,25,25,25$ and $20 \mathrm{~mm}$, respectively).Compounds $21 \mathrm{c}$, 21d and $18 \mathrm{~b}$ exhibited moderate activity (16, 19 and 18mm, respectively). Compounds $\mathbf{1 0 ,} \mathbf{5 , 1 3}$ and $\mathbf{1 7}$ were considered as the weak antifungal compounds (13, 12, 12 and $12 \mathrm{~mm}$, respectively). Compounds 4, 15, 16, 21b and 21c did not exhibit any antimicrobial activity against any tested pathogenic test microbes.

Table 1: Antimicrobial activity of the newly synthesized coumarin derivatives against different test microbes.

\begin{tabular}{|c|c|c|c|c|}
\hline \multirow[b]{2}{*}{ Sample } & \multicolumn{4}{|c|}{ Clear zone $(\phi \mathrm{mm})$} \\
\hline & Aspergillusniger & 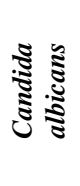 & 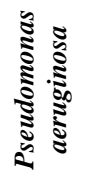 & 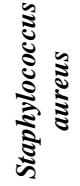 \\
\hline Neomycin $100 \mu \mathrm{g}$ & 0 & 25 & 23 & 22 \\
\hline Cycloheximide $100 \mu \mathrm{g}$ & 35 & 0 & 0 & 0 \\
\hline 2 & 0 & 19 & 20 & 15 \\
\hline 3 & 25 & 18 & 18 & 13 \\
\hline 4 & 0 & 0 & 0 & 0 \\
\hline 5 & 12 & 18 & 17 & 15 \\
\hline 6 & 0 & 0 & 0 & 0 \\
\hline 10 & 13 & 18 & 19 & 15 \\
\hline 13 & 12 & 13 & 0 & 12 \\
\hline 14 & 0 & 13 & 14 & 13 \\
\hline 15 & 0 & 0 & 0 & 0 \\
\hline 16 & 0 & 0 & 0 & 0 \\
\hline 17 & 12 & 18 & 17 & 15 \\
\hline $18 \mathrm{a}$ & 20 & 14 & 15 & 13 \\
\hline $18 \mathrm{~b}$ & 18 & 20 & 19 & 20 \\
\hline $20 \mathrm{a}$ & 0 & 12 & 12 & 14 \\
\hline $20 \mathrm{~b}$ & 32 & 0 & 18 & 25 \\
\hline $20 \mathrm{c}$ & 25 & 17 & 16 & 18 \\
\hline $20 \mathrm{~d}$ & 25 & 14 & 15 & 17 \\
\hline $21 \mathrm{a}$ & 0 & 0 & 14 & 0 \\
\hline $21 b$ & 0 & 0 & 0 & 0 \\
\hline $21 \mathrm{c}$ & 16 & 0 & 0 & 0 \\
\hline $21 \mathrm{~d}$ & 19 & 19 & 20 & 14 \\
\hline
\end{tabular}

\section{Antioxidant screening assay}

Free radicals of different forms are constantly generated for specific metabolic requirement and disposed by an efficient antioxidant network in the body. Free radicals are unstable, so when the generation of these species exceeds the levels of antioxidant mechanism, they can damage cells, proteins and other genetic materials, such as DNA, leads to oxidative damage of tissues and organs, thus leading to many health-related problems. Eventually, their effects lead to chronic diseases, especially degenerative diseases. Many coumarins have a great ability to scavenge reactive oxygen species (ROS)-free radicals, such as superoxide radicals, hydroxyl radicals or hypochlorous acid and to influence processes involving free radical-injury (Gutteridge, 1995).

The scavenging activity for DPPH free radicals was measured according to Zhao et al. (2006), with some modifications. Some of the newly synthesized three substituted coumarins showed antioxidant effect as shown in Table 2. Comparing with Ascorbic acid, compounds 3,10, 14, 20b, 20c and21b exhibited the strongest antioxidant efficacy in the tested compounds. While compounds $2,5,13,15,18 a, 18 b, 20 a, 21 a$ and 21c showed a moderate antioxidant activity. The rest of the compounds showed week antioxidant activity. From the structure activity relationship (SAR) it is noticeable that compound $\mathbf{3}$ have cyano group attached to the pyridine ring and compound $\mathbf{2 0 b}$ have 
nitro and ester groups attached to the pyrazole ring which may have a special ability to scavenge reactive oxygen species and hence protect the cells from DNA damage.

Table 2: Antioxidant activity assay.

\begin{tabular}{ccc}
\hline Sample & Absorbance & \% Inhibition \\
\hline 2 & 0.072 & 88.7 \\
3 & 0.0365 & 94.3 \\
4 & 0.3 & 53 \\
5 & 0.17 & 73.4 \\
6 & 0.435 & 31.92 \\
10 & 0.049 & 92.33 \\
13 & 0.16 & 75 \\
14 & 0.063 & 90.14 \\
15 & 0.114 & 82.2 \\
16 & 0.45 & 29.6 \\
17 & 0.588 & 8 \\
$18 \mathrm{a}$ & 0.077 & 87.9 \\
$18 \mathrm{~b}$ & 0.09 & 85.92 \\
$20 \mathrm{a}$ & 0.08 & 87.5 \\
$20 \mathrm{~b}$ & 0.035 & 94.52 \\
$20 \mathrm{c}$ & 0.04 & 93.74 \\
$20 \mathrm{~d}$ & 0.33 & 48.36 \\
$21 \mathrm{a}$ & 0.064 & 89.9 \\
21b & 0.04 & 93.74 \\
21c & 0.109 & 82.94 \\
$21 \mathrm{~d}$ & 0.323 & 49.5 \\
Ascorbic acid & 0.038 & 96 \\
\hline & &
\end{tabular}

\section{Cytotoxicity evaluation}

Half maximal inhibitory concentration $\left(\mathrm{IC}_{50}\right)$ in pharmacological research is the factor used to evaluate antagonist drug potency and the effect of dose-response curve of different concentrations of drug on mammalian cell line growth will postulate the $\mathrm{IC}_{50}$ (Cheng and Prusoff,1973; Lazareno and Birdsall,1993). According to the National Cancer Institute (NCI), the criteria and the conditions of cytotoxic activity for the crude extract is an $\mathrm{IC}_{50}$ values $\leq 20 \mu \mathrm{g} / \mathrm{ml}$, is considered to be potentially cytotoxic. The criteria used to categorize the cytotoxicity of isolated fractions against mammalian cell lines, based on U.S. National Cancer Institute (NCI) and Geran protocol, was as follows: $\mathrm{IC}_{50} \leq 20 \mu \mathrm{g} / \mathrm{ml}=$ highly cytotoxic, $\mathrm{IC}_{50} 21-100 \mu \mathrm{g} / \mathrm{ml}=$ moderately cytotoxic, $\mathrm{IC}_{50} 101-200 \mu \mathrm{g} / \mathrm{ml}=$ weakly cytotoxic and $\mathrm{IC}_{50}>501 \mu \mathrm{g} / \mathrm{ml}=$ no cytotoxic (Geran,1972; Boik, 2001). The synthesized new 3-substituted coumarin derivatives were evaluated for their in vitro cytotoxic potentiality against mammalian cell line. Three concentrations $100 \mu \mathrm{g} / \mathrm{ml}, 50 / \mathrm{ml} \mu \mathrm{g}$ and $10 \mu \mathrm{g} / \mathrm{ml}$ of newly synthesized coumarin derivatives were used to determine the cytotoxic effect on Vero cell line in compare with the control free of derivatives.

Referring to Table (3) it was found that compounds 2,3 , 6, 13, 14, 16, 17, 18b, 20c, 21a, 21b, 21c showed moderately cytotoxic effect while compounds 4, 15, 18a, 20b exhibited weakly cytotoxic activity. But compounds 5, 10, 20d showed moderately to high cytotoxic effect and compounds 20a, 21d showed highly cytotoxic effect.

From the structure activity relationship (SAR), it is remarkable that compound 20a has chloro and ester groups attached to the pyrazole ring and compound 21d has methyl and nitro groups attached to the pyridazine ring which may responsible for their high cytotoxic effect.

Table 3: Cytotoxicity evaluation using concentrations 100, 50,10 $\mu \mathrm{g}$ respectively of the newly synthesized coumarin derivatives against Vero cell line and calculation the equivalent concentration to $\mathrm{IC}_{50}$ for each.

\begin{tabular}{|c|c|c|c|c|c|c|c|}
\hline Sample & $\begin{array}{l}\text { Mean conc. } \\
100 \mu \mathrm{g}\end{array}$ & $\begin{array}{c}\text { Mean conc. } 50 \\
\mu \mathrm{g}\end{array}$ & $\begin{array}{c}\text { Mean conc. } 10 \\
\mu \mathrm{g}\end{array}$ & Equation & $\begin{array}{l}\text { Mean } \\
\text { control }\end{array}$ & control IC50 & $\begin{array}{l}\text { Conc. equivalent to } \\
\text { IC50 } \mu \mathrm{g}\end{array}$ \\
\hline 2 & 0.142 & 0.269 & 0.429 & $\mathrm{y}=313.54 \mathrm{x}-34.459$ & 0.581 & 0.2905 & 56.46 \\
\hline 3 & 0.495 & 0.516 & 0.683 & $y=410.06 x-101.21$ & 0.689 & 0.3445 & 40.05 \\
\hline 4 & 0.967 & 0.564 & 0.412 & $y=-149.27 x+150.01$ & 0.642 & 0.321 & 102 \\
\hline 5 & 0.451 & 0.228 & 0.645 & $y=112.5 x+3.6851$ & 0.492 & 0.246 & 31.36 \\
\hline 6 & 0.671 & 0.186 & 0.685 & $y=14.058 x+46.108$ & 0.693 & 0.3465 & 50.97 \\
\hline 10 & 0.21 & 0.735 & 0.464 & $y=73.287 x+18.913$ & 0.546 & 0.273 & 38.9 \\
\hline 13 & 0.51 & 0.888 & 0.482 & $y=-24.959 x+68.974$ & 0.473 & 0.2365 & 63.1 \\
\hline 14 & 0.66 & 0.366 & 0.607 & $y=-30.409 x+69.886$ & 0.453 & 0.2265 & 62.99 \\
\hline 15 & 0.677 & 0.152 & 0.265 & $y=-114.44 x+95.066$ & 0.547 & 0.2735 & 126.2 \\
\hline 16 & 0.203 & 0.158 & 0.822 & $y=105.45 x+11.751$ & 0.682 & 0.341 & 47.7 \\
\hline 17 & 0.463 & 0.52 & 0.08 & $y=-157.74 x+109.23$ & 0.629 & 0.3145 & 59.699 \\
\hline $18 \mathbf{a}$ & 0.44 & 0.515 & 0.591 & $y=596.16 x+253.89$ & 0.544 & 0.272 & 416 \\
\hline $18 \mathrm{~b}$ & 0.078 & 0.103 & 0.591 & $y=142.59 x+16.641$ & 0.538 & 0.269 & 54.95 \\
\hline 20a & 0.228 & 0.162 & 0.062 & $y=-538.75 x+134.5$ & 0.562 & 0.281 & -16.88 \\
\hline $20 \mathrm{~b}$ & 2.341 & 1.641 & 0.953 & $y=-64.819 x+159.96$ & 0.57 & 0.285 & 141.48 \\
\hline 20c & 0.623 & 0.591 & 0.128 & $y=-149.82 x+120.35$ & 0.499 & 0.2495 & 82.97 \\
\hline 20d & 0.187 & 0.28 & 0.119 & $y=-266.62 x+105.41$ & 0.477 & 0.2385 & 41.82 \\
\hline $21 \mathbf{a}$ & 1.18 & 1.7 & 0.897 & $y=-45.032 x+110.03$ & 0.466 & 0.233 & 99.53 \\
\hline $21 b$ & 1.582 & 0.271 & 0.354 & $y=-49.113 x+89.464$ & 0.469 & 0.2345 & 77.94 \\
\hline $21 \mathrm{c}$ & 0.197 & 0.289 & 0.319 & $y=666.45 x-125.5$ & 0.531 & 0.2655 & 51.44 \\
\hline 21d & 0.085 & 0.075 & 0.065 & $\mathrm{y}=-4500 \mathrm{x}+390.83$ & 0.668 & 0.334 & -1112 \\
\hline
\end{tabular}

(y) Is the concentration equivalent to IC50 per $\mu \mathrm{g}$ and (x) is the control IC50 Absorbance at wave length $630 \mathrm{~nm}$. 


\section{CONCLUSION}

The new compounds exhibited promising biological activities and seem to be interesting for further pharmaceutical studies. In addition, the present studies elucidate new methods for synthesis of new substituted coumarin derivatives. Most of the newly synthesized compounds showed strong efficacy against most of the tested microorganisms in case of compound $20 \mathbf{b}$ the activity was stronger than the tested standard drug itself. Also, most of the new derivatives exhibited excellent results when they evaluated for their antioxidant activity like compounds 3, 10, 14, 20b, 20c and 21b which showed strong antioxidant activity when compared to the ascorbic acid.Moreover,compounds 5, 10, 20d showed moderately to high cytotoxic effect and compounds $\mathbf{2 0 a}$, 21d showed highly cytotoxic effect. So, synthesis of new coumarins and evaluation of their biological and pharmaceutical importance still an active area for more investigations.

\section{Financial support and sponsorship: Nil.}

Conflict of Interests: There are no conflicts of interest.

\section{REFERENCES}

Abdel-Rahman A E, Bakhite E A,Al-Taifi E A. Synthesis and antimicrobial testing of some new S-substituted Thiopyridines, Thienopyridines, Pyridothienopyrimidines and Pyridothienotriazines. Pharmazie, 2003; 58: 372-377.

Abdel-Aziz M S,Shaheen M S,EL-Nekeety A A, Abdel WahhabM A. Antioxidant and antibacterial activity of silver nanoparticles biosynthesized using Chenopodium murale leaf extract. J Saudi Chem Soc, 2014; 18: 356-363.

Al-Zaydi K M. Microwave assisted synthesis, Part 1: Rapid solventless synthesis of 3-substituted Coumarins and Benzocoumarins by microwave irradiation of the corresponding enaminones. Molecules, 2003; 8: 541-555.

Barry A L. 1976, The antimicrobial susceptibility test, principle and practices, 4th edn., ELBS, London: 180.

Baudoin R, Corlu A, Griscom L, Legallais C, Leclerc E. Trends in the development of microfluidic cell biochips for in vitro hepatotoxicity.Toxicology in Vitro, 2007; 21 (4): 535-544.

Boik J. Natural Compounds in Cancer Therapy .Oregon Medical Press, Princeton, MN, USA, 2001.pp. 25.

Cheng Y, Prusoff W H. Relationship between the inhibition constant (KI) and the concentration of inhibitor which causes 50 per cent inhibition (I50) of an enzymatic reaction. Biochem Pharmacol, 1973; 22 (23): 3099-3108.

Dean FM. Naturally occurring Cumarins, For Chem. Org. Nat., 1952; 9: 225-232.

Geran RI. Protocols for screening chemical agents and natural products against animal tumors and other biological systems. Cancer Chemother Rep, 1972; 3: 51-61.

Gutteridge J MC. Evaluation of anti-inflammatory and antioxidant potential of the kernel root. Free Radic Res Comm, 1995; 19:141-1583.

Hassan M, Van der leilie D, Springael D, Römling U, Ahmed N, Mergeay M., Identification of a gene cluster, czr, involved in cadmium and zinc resistance in Pseudomonas aeruginosa, Gene, 1999 ; 238:417425 .

Himmel H. Tris (2,2'biopyridine) ruthenium (II) using common biological buffers as co-reactant, $\mathrm{pH}$ buffer and supporting electrolyte, Royal Soc Chem.140: 7142-7145.

Kennedy R O, Thornes RD, Counarins : Biology, Applications and Mode of Action, 1997, Wiley \& Sons.
Lazareno S, Birdsall,N J. Estimation of competitive antagonist affinity from functional inhibition curves using the Gaddum, Schild and Cheng-Prusoff equations. Brit J Pharmacol, 1993; 109 (4): 1110-1119.

Lerner S A. Resolving the antibiotic paradox .Adv Exper Med Biol, 1998; 456: 7-15.

Li Z, Hu J, Sun M, Ji H, Chu S, Liu G et al. Antiinflammatory effect of IMMLG5521, a coumarin derivative, on Sephadex-induced lung inflammation in rats. Inter Immunopharmacol, 2012; 14: 145-149.

Medzhitov R. Inflammation: new adventures of an old flame. Cell, 2010; 140: 771-776.

Mislaine A B, Celso V N , Benedito P D F, Tânia U, Maria C M, Diógenes A C. Antileishmanial activity of crude extract and coumarin from Calophyllum brasiliense leaves against Leishmania amazonensis. Parasitology Research, 2017; 101(3):715-722.

Ouattara D A, Choi S-H, Sakai Y, Pery A R R, Brochot C. Kinetic modelling of in vitro cell-based assays to characterize non-specific bindings and ADME processes in a static and a perfused fluidic system. Toxicol Lett, 2011; 205 (3): 310-319.

Panlilio A L, Culver D H, Gaynes R P. Methicillin-resistant Staphylococcus aureus in U.S. hospitals, 1975-1991. Infect Cont Hosp Epidemiol, 1992; 13: 582-586.

Phelan M. 2007, Basic techniques in mammalian cell tissue culture. Curr Protoc Cell Biol. Chapter 1(Unit 1.1).

Ping-Ping S, Jun Z, Zong-Liang L, Ya-Bing D, Yi-Ping $\mathrm{H}$, Chun-Qing Z, Min W, Min W, Nian-He W, Ye L, Zhao-Jun H. Evaluation of antifungal activities and structure-activity relationships of coumarin derivatives. Pest Management Science 2017, 73 (1): 94-101.

Salem MAI, Marzouk MI, El-Kazak A M. Anticancer activity of new coumarin substituted hydrazide-hydrazone derivatives. Molecules, 2016; $21: 249$.

Shwu-Chen T, Shu-Yu L, Wen-Chieh H, Ming-Hua H, Kuo Chu H, Chun-Cheng L, Jia-Cherng H, I-Chia C, JihRu H, Fa-KuenSh, Pieter L, Johan N. Antibacterial and cytotoxic activity of isoprenylated coumarinmammea A/AA isolated from Mammea Africana. Molecules, 2016; $21: 228$.

Shawlli A S, Abdelhamid A O. Reaction of dimethylphenacylsulfonium bromide with $\mathrm{N}$-nitrosoacetarylamides and reactions of the products with nucleophiles. Bull Soc Chem Jpn, 1976; 49: 321-332.

Silva AC, Delgado I, Sousa MF, Carrondo MJ, Alves PM. Scalable culture systems using different cell lines for the production of peste des Petits Ruminants vaccine. Vaccine, 2008; 26:3305-3311.

Suffness M, Pezzuto J M.1990, Assays related to cancer drug discovery. In: Hostettmann, K. (Ed.), Methods Plant Biochem: Assays Bioact; 6: 71-133.

Sung O L, Sang Z Ch, Jong H L, Sung H Ch, Sang H P, Hee Ch K, Eun Y Y , Hi J C, Kang R L. Antidiabetic coumarin and cyclitol compounds fromPeucedanum japonicum. Archives of Pharmacal Research, 2017; 27(12):1207-1210.

Witaicenis A,SeitoL N,da Silveira Chagas A, de Almeida Junior L D,Luchini AC, Rodrigues-Orsi P et al. Antioxidant and intestinal antiinflammatory effects of plant-derived coumarin derivatives. Phytomed, 2014; 21: 240-246.

Zhao G R, Xiang Z J,Ye T X,YaunJ Y, GuoX Z.Antioxidant activities of Salvia miltiorrhiza and Panaxnoto ginseng. Food Chem, 2006; 99: 767-774.

\section{How to cite this article:}

Rashdan HM, Nasr SM, El-Refai HA, Abdel-Aziz MS. A Novel Approach of Potent Antioxidant and Antimicrobial Agents Containing Coumarin Moiety Accompanied with Cytotoxicity Studies on The Newly Synthesized Derivatives. J App Pharm Sci, 2017; 7 (07): 186-196. 